\title{
Article
}

\section{Investigation of Permeable Reactive Barrier Design Parameters for Remediating Fluoride-Contaminated Groundwater using a Volcanic Ash Soil Adsorbent}

\author{
Takaaki SHINOHARA*, Mamoru IWASAKI \\ Kurita Water Industries Ltd., 1-1, Kawada, Nogi-machi, Shimotsuga-gun, Tochigi 329-0105, Japan
}

(Manuscript received July 2, 2014; Accepted August 5, 2014)

\begin{abstract}
Permeable reactive barriers (PRBs) are a technology for remediating groundwater contaminated with hazardous substances. Fluoride compounds are specified as hazardous substances by Japanese environmental standards. Currently there are no suitable materials applicable to PRB for removing fluoride; hence, we present an adsorbent prepared inexpensively from volcanic ash soil (VAS) as a PRB material. The purpose of this work was to clarify whether VAS is an applicable PRB material to remove fluoride from groundwater. VAS consists of aluminum oxide, silicon oxide, and iron oxide. Previous reports have suggested that the mechanism of fluoride adsorption onto VAS involves an ion-exchange reaction with the active hydroxyl groups of the metal oxides. The present study successfully confirmed the ion-exchange mechanism through batch-wise adsorption experiments. We also confirmed that VAS has a higher adsorption selectivity for fluoride than for the common components in groundwater. Because of the ion-exchange mechanism, the ordinary Langmuir equation cannot be applied to describe the adsorption behavior when the $\mathrm{pH}$ differs between batch-wise and column experiments. Therefore, we introduced the modified Langmuir adsorption isotherm, which considers the $\mathrm{pH}$ of the aqueous solution at equilibrium to predict the amount of fluoride adsorbed in the column experiment. Column experiments were also conducted to obtain the rate of fluoride adsorption onto VAS. The overall mass transfer coefficient was estimated from experimental breakthrough data by numerical analysis. We obtained both the equilibrium and the kinetic parameters of fluoride adsorption onto VAS for the design of a PRB for removing fluoride from groundwater.
\end{abstract}

Keywords: Permeable Reactive Barrier, Fluoride, Ion exchange, Volcanic Ash Soil

\begin{abstract}
1. Introduction
Permeable reactive barriers (PRBs) are one of the technologies for remediating groundwater contaminated with hazardous organic and inorganic substances. ${ }^{1)}$ Fig. 1 shows a schematic diagram of a PRB. Contaminants are removed from groundwater due to self-degradation or adsorption. Generally, granular zero-valent iron has been used as a PRB material for removing these contaminants, although it cannot remove
\end{abstract}

fluoride. The application of ion-exchange resins or inorganic adsorbents such as hydrotalcite, ${ }^{2)}$ calcite, ${ }^{3-4)}$ and bauxite ${ }^{5)}$ for the removal of fluoride can be considered; however, these ionexchangers are very costly and many of the inorganic adsorbents commercially available cannot be applied to a PRB because their power form results in decreasing permeability. In this study, we examined an adsorbent prepared inexpensively from volcanic ash soil (VAS). The adsorption mechanism and

\footnotetext{
* Corresponding author

E-mail: takaaki.shinohara@kurita.co.jp
} 
adsorption parameters were investigated to design a PRB.

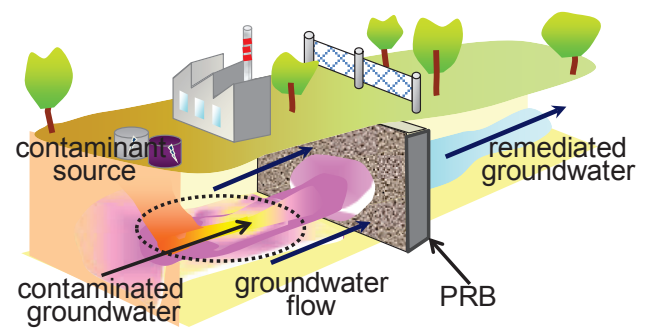

Fig. 1 Schematic diagram of a PRB.

\section{Experimental}

\subsection{Materials}

The VAS adsorbent was prepared by baking allophane soil mixed with iron(II) sulfate. All other chemical substances used in this study were analytical grade reagents.

\subsection{Preparation of simulated groundwater}

The experiments were conducted using simulated groundwater made from pure water dosed with components that are commonly contained in groundwater. For reference, the experiments were conducted with both the sodium fluoride aqueous solution and the polluted groundwater. The composition of the simulated groundwater is shown in Table $\mathbf{1}$. The simulated groundwater was prepared by dissolving sodium fluoride, calcium chloride, magnesium chloride, sodium metasilicate, sodium hydrogen carbonate, potassium hydrogen carbonate, hydrochloric acid, and sulfuric acid into pure water.

Table 1 The composition of simulated groundwater.

\begin{tabular}{|c|c|c|}
\hline \multicolumn{2}{|c|}{ lon species } & $\overline{(\mathrm{m} m \mathrm{mo} / / \overline{\mathrm{L}})}-\frac{\text { Concentration }}{(\mathrm{mg} / \mathrm{L})}$ \\
\hline $\begin{array}{l}\text { Cation } \\
\text { species }\end{array}$ & $\begin{array}{l}\mathrm{Na}^{+}- \\
\mathrm{K}^{+}- \\
-\mathrm{Ca}^{2+}-- \\
-\mathrm{Mg}^{2+}-\end{array}$ & 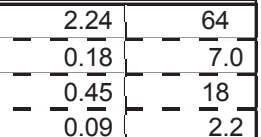 \\
\hline \multirow[t]{2}{*}{$\begin{array}{l}\text { Anion } \\
\text { species }\end{array}$} & \begin{tabular}{|l}
$\mathrm{F}-$ \\
$-\mathrm{HCO}_{3}^{-}-$ \\
$\mathrm{Cl}^{-}-$ \\
$-\mathrm{SO}_{4}{ }^{2-}-$ \\
\end{tabular} & 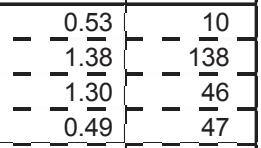 \\
\hline & $\mathrm{SiO}_{3}{ }^{2-}$ & $0 . \overline{52} \Gamma-\overline{31}$ \\
\hline
\end{tabular}

\subsection{Batch-wise adsorption experiments}

To evaluate the fluoride adsorption ability, batch-wise experiments were conducted. Predetermined quantities of VAS were measured into polyethylene bottles and then sodium fluoride solution, simulated groundwater or polluted groundwater was added. The bottles were shaken on a rotary shaker at $160 \mathrm{rpm}$ for $72 \mathrm{~h}$ at room temperature and filtrated through a membrane with $0.45-\mu \mathrm{m}$ pore size. The fluoride concentration in the filtrate was measured using the lanthanumalizarin complexone method.

\subsection{Column experiments}

Considering the practical system, we conducted column adsorption tests under continuous water-flow conditions through a column packed with VAS in order to observe the behavior of fluoride removal. A schematic of the column experiment is shown in Fig. 2.

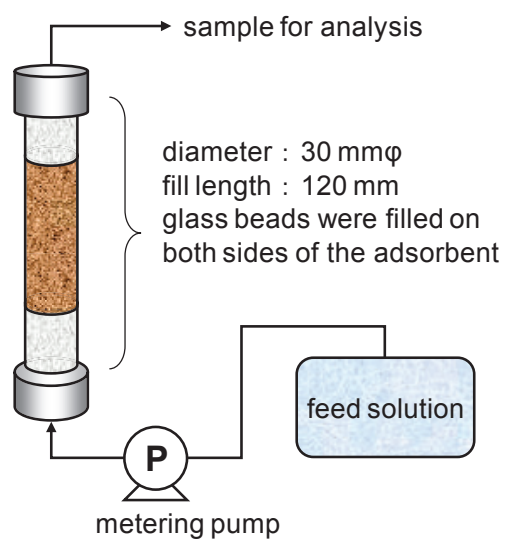

Fig. 2 Schematic diagram for the column experiments.

A $200-\mathrm{mm}$ tall acrylic column with a $30-\mathrm{mm}$ inner diameter was used for the packed column. A 120-mm section of the column was filled with VAS and the remaining space either side of the VAS was filled with glass beads. Feed solution was continuously fed from the bottom of the packed bed in up-flow mode.

\section{Results and Discussion}

\subsection{Physical properties of the adsorbent}

Table 2 shows the chemical composition and the physical properties of the VAS.

Table 2 Physical properties of the VAS.

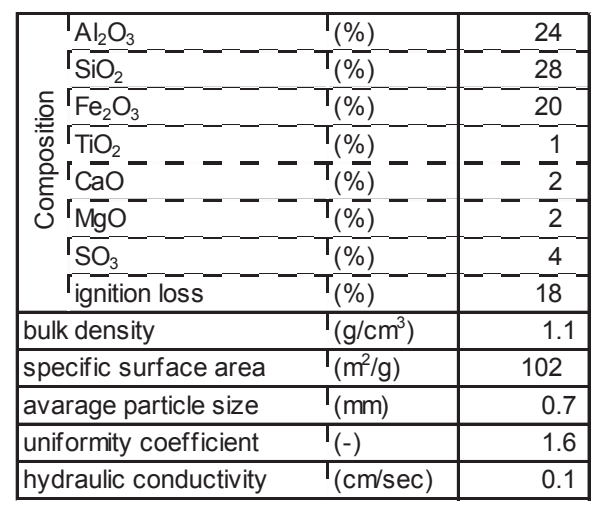

Alumina, silica, and iron oxides are the major component materials of VAS because it is processed by baking allophane soil with iron sulfate. The fluoride adsorption mechanism is considered to be ion exchange with the active hydroxyl groups bonding to aluminum and iron atoms. VAS has a large specific 
surface area, $102 \mathrm{~m}^{2} / \mathrm{g}$, and has appropriate physical properties to provide good permeability. The average particle diameter, uniformity coefficient, and hydraulic conductivity are $0.7 \mathrm{~cm}$, 1.6 , and $80 \mathrm{~m} / \mathrm{d}$, respectively. Generally, sandy aquifer having good permeability has the hydraulic conductivity of $10 \mathrm{~m} / \mathrm{d}$. These hydraulic properties are suitable for applying the material to a PRB.

\subsection{Batch-wise adsorption results}

Fig. 3 shows the results of the batch adsorption tests conducted by adding simulated groundwater with a fluoride concentration of $10 \mathrm{mg} / \mathrm{L}$ to a predetermined amount of adsorbent. The horizontal axis is fluoride concentration of the aqueous solution at equilibrium, and the vertical axis is the amount of fluoride adsorbed per unit weight of VAS.

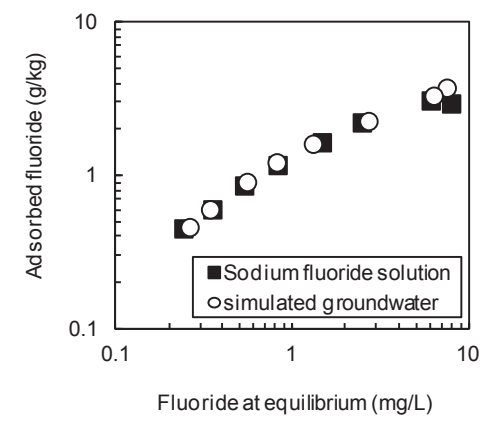

Fig. 3 Adsorption isotherm of fluoride.

No significant difference in fluoride adsorption behavior was observed between the simulated groundwater and the aqueous solution containing only sodium fluoride. This indicates that the coexisting components chloride, sulfate, and carbonate ions in the simulated groundwater did not affect the adsorption of fluoride ion onto the VAS. It is understood that VAS provides selectivity regarding fluoride adsorption under the present experimental condition.

In general, the adsorption behavior caused by the ionexchange reaction can be described by the Langmuir adsorption equation expressed in equation (Eq.) 1, where $q_{\mathrm{e}}$ is the equilibrium adsorption amount, $q_{\mathrm{t}}$ is the maximum adsorption amount, $k$ is the Langmuir constant, and $C$ is the equilibrium concentration in solution.

$$
q_{e}=\frac{q_{t} \cdot k \cdot C}{1+k \cdot C}
$$

The values of $k$ and $q_{\mathrm{t}}$ in Eq. 1 were determined by the method of least squares so that the calculated results would show good agreement with the experimental results. The values were $0.38 \mathrm{~L} / \mathrm{g}$ and $4.9 \mathrm{mg} / \mathrm{g}$, respectively.

The adsorption behavior of fluoride ions on VAS is apparently expressed by the Langmuir adsorption isotherm; although the $\mathrm{pH}$ of the aqueous solution at equilibrium for each data is different, as shown in Fig. 5. Consequently, this adsorption phenomenon is affected by the $\mathrm{pH}$ of the aqueous solution at equilibrium, which is discussed in next section.

\subsection{Reaction mechanism of fluoride adsorption by VAS}

The fluoride adsorption reaction with VAS is described by Eq. 2. In this formula, $\overline{\mathrm{R}-\mathrm{OH}}$ is an $\mathrm{OH}$-type ion-exchange group on VAS, and $\overline{\mathrm{R}-\mathrm{F}}$ is an F-type group.

$$
\overline{\mathrm{R}-\mathrm{OH}}+\mathrm{F}^{-} \stackrel{K}{\stackrel{\mathrm{ex}}{\longleftrightarrow}} \overline{\mathrm{R}-\mathrm{F}}+\mathrm{OH}^{-}
$$

The equilibrium constant, $K_{\mathrm{ex}}$, is expressed in Eq. 3, where $\left[\mathrm{OH}^{-}\right]$is the hydroxide ion concentration in aqueous solution, $\left[\mathrm{F}^{-}\right]$is the fluoride ion concentration in aqueous solution, $[\overline{\mathrm{R}-\mathrm{F}}]$ is the amount of F-type ion-exchange group per unit weight of VAS, and $[\overline{\mathrm{R}-\mathrm{OH}]}$ is the amount of OH-type ionexchange group per unit weight of VAS.

$$
K_{\mathrm{ex}}=\frac{[\overline{\mathrm{R}-\mathrm{F}}]\left[\mathrm{OH}^{-}\right]}{[\overline{\mathrm{R}-\mathrm{OH}}]\left[\mathrm{F}^{-}\right]}
$$

The distribution coefficient $D$ is defined by $[\overline{\mathrm{R}-\mathrm{F}}] /\left[\mathrm{F}^{-}\right]$, and $K_{\text {ex }}$ ' is rewritten as $K_{\text {ex }}[\overline{\mathrm{R}-\mathrm{OH}}] / K_{\mathrm{w}}$, where $K_{\mathrm{W}}$ is the ionic product of water. Here, we assumed that $[\overline{\mathrm{R}-\mathrm{OH}}]$ is sufficiently larger than adsorbed fluoride. Then Eq. 4 is obtained by derivation from Eq. 3 .

$$
\log D=\log K_{\text {ex }}{ }^{\prime}-\mathrm{pH}
$$

Fig. 4 shows the relationship between the logarithm of $D$ and the equilibrium $\mathrm{pH}$ obtained from batch-wise adsorption experiments.

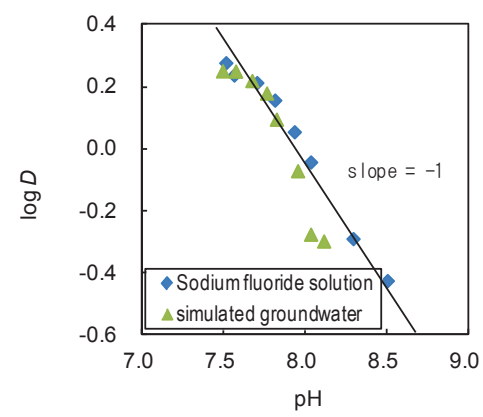

Fig. 4 The effect of equilibrium $\mathrm{pH}$ on $\log D$.

The logarithm of $D$ shows a proportional relationship to $\mathrm{pH}$ with a slope of negative 1 . Therefore, the fluoride adsorption on VAS progresses by the ion-exchange mechanism shown in Eq. 2 whereby

$[\overline{\mathrm{R}-\mathrm{F}}]$ and $[\overline{\mathrm{R}-\mathrm{OH}}]$ can be described as follows with $q_{\mathrm{e}}$ 
and $q_{\mathrm{t}}$ respectively:

$$
\begin{aligned}
& q_{e}=[\overline{\mathrm{R}-\mathrm{F}}] \\
& q_{t}-q_{e}=[\overline{\mathrm{R}-\mathrm{OH}}]
\end{aligned}
$$

By substituting Eq. 5 and 6 into Eq. 3, Eq. 7 is provided.

$$
q_{e}=\frac{q_{t} \cdot\left[\mathrm{F}^{-}\right] \cdot K_{e x} /\left[\mathrm{OH}^{-}\right]}{1+\left[\mathrm{F}^{-}\right] \cdot K_{e x} /\left[\mathrm{OH}^{-}\right]}
$$

Equation 7 corresponds to the Langmuir adsorption isotherm with consideration of the aqueous solution $\mathrm{pH}$ at equilibrium. The values of $K_{\mathrm{ex}}$ and $q_{\mathrm{t}}$ in Eq. 7 were determined by the method of least squares so that the calculated results would show good agreement with the experimental results. The values were $2.1 \times 10^{-3}$ and $0.5 \mathrm{~mol} / \mathrm{kg}$, respectively.

Fig. 5 indicates the adsorption isotherm of fluoride obtained from the experimental data, and shows the calculated results provided by substituting the determined values of $K_{\mathrm{ex}}$ and $q_{\mathrm{t}}$ into Eq. 7. We clarified that the value predicted by Eq. 7 and the experimental data show good agreement with each other. Consequently, we present evidence to show that the fluoride adsorption behavior of this adsorbent can be explained by Eq. 7, which considers the $\mathrm{pH}$ of the aqueous solution at equilibrium.

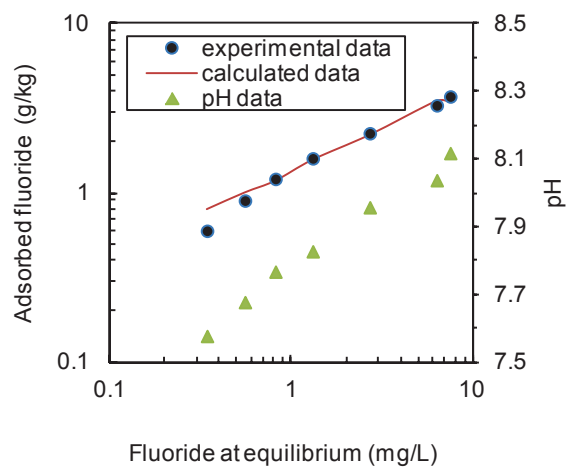

Fig. 5 Comparison between experimental results and the calculated results obtained from Eq. 7.

\subsection{Column operation results}

Packed column experiments were conducted to confirm the behavior of fluoride removal by VAS applied to a PRB under continuous water-flow conditions. Simulated groundwater containing $4 \mathrm{mg} / \mathrm{L}$ of fluoride ion was fed from the bottom into the column packed with VAS in up-flow mode with a velocity of $20 \mathrm{~cm} / \mathrm{d}$.

Fig. 6 shows an example of the column experimental results.

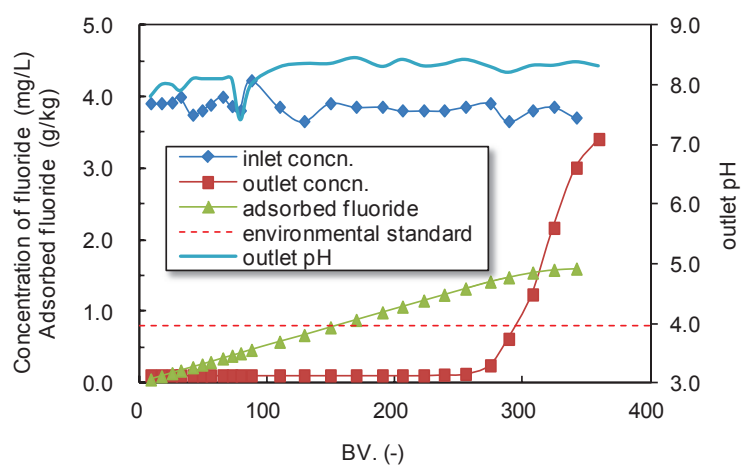

Fig. 6 Column experimental result.

Under the continuous water-feed condition, we obtained treated water with a fluoride concentration lower than the target given by Japanese environmental standards $(<0.8 \mathrm{mg} / \mathrm{L})$.

The breakthrough point on fluoride was observed at about $270 \mathrm{BV}$, then the fluoride concentration reached the target given in the Japanese standards at $300 \mathrm{BV}$. At this point, more than $1.5 \mathrm{~g} / \mathrm{kg}$ of total adsorbed fluoride was attained. By using Eq. 7, we calculated that $1.8 \mathrm{~g} / \mathrm{kg}$ was adsorbed at equilibrium from an aqueous solution containing $4 \mathrm{mg} / \mathrm{L}$ fluoride. The amount of fluoride adsorbed cumulatively on the VAS in the column experiment was approximately equal to the amount adsorbed at equilibrium when calculated from Eq. 7.

On the other hand, the amount adsorbed at equilibrium calculated using the ordinary Langmuir isotherm (Eq. 1) gave $2.9 \mathrm{~g} / \mathrm{kg}$ at the same fluoride concentration $(4 \mathrm{mg} / \mathrm{L})$. Based on this result, it is clear that consideration of $\mathrm{pH}$ is required when calculating the amount adsorbed at equilibrium in batch-wise tests.

Experimental results from the column were also utilized to obtain the overall mass transfer coefficient $\left(K_{\mathrm{f}} a_{\mathrm{v}}\right),{ }^{6-7)}$ which is a kinetic parameter. The parameter $K_{\mathrm{f}} a_{\mathrm{v}}$ was determined to $100 \mathrm{~d}^{-1}$ by a numerical analysis based on Eqs 8 and 9 to provide simulation results with good agreement with the experimental breakthrough data.

$$
\begin{aligned}
& Z a=\frac{u}{K_{f} a_{v}} \int_{C_{B}}^{C_{0}-C_{B}} \frac{d C}{C-C^{*}} \\
& T_{\mathrm{B}}=\frac{q_{0} Z}{u C_{0}}\left(1-\frac{Z a}{2 Z}\right)
\end{aligned}
$$

where $Z a$ is the length of adsorption band, $u$ is the linear velocity of water, $C_{0}$ is the inlet fluoride concentration., $C_{\mathbf{B}}$ is the breakthrough concentration, $C$ is the outlet fluoride concentration, $C^{*}$ is the liquid phase concentration of fluoride in equilibrium with adsorption amount at the given axial position $\mathrm{z}, T_{\mathrm{B}}$ is the breakthrough time to give $C=C_{\mathrm{B}}, q_{0}$ is the amount adsorbed at equilibrium with the inlet concentration 
$C_{0}$, and $Z$ is the packing length of the adsorbent.

Fig. 7 shows the comparison between the simulation results based on Eq. 8 and Eq. 9 and the column experimental data. In Fig. 7, two simulation results are indicated; one is the result from applying the ordinary Langmuir isotherm, and the other is the result from applying the modified Langmuir isotherm that considers the dependency on $\mathrm{pH}$. Although $K_{\mathrm{f}} a_{\mathrm{v}}$ is fixed to 100 $\mathrm{d}^{-1}$ for both simulations, the results are significantly influenced by the type of isotherm. Consequently, the isotherm considering $\mathrm{pH}$ is appropriate to evaluate the performance of VAS applied to PRB for removing fluoride from groundwater.

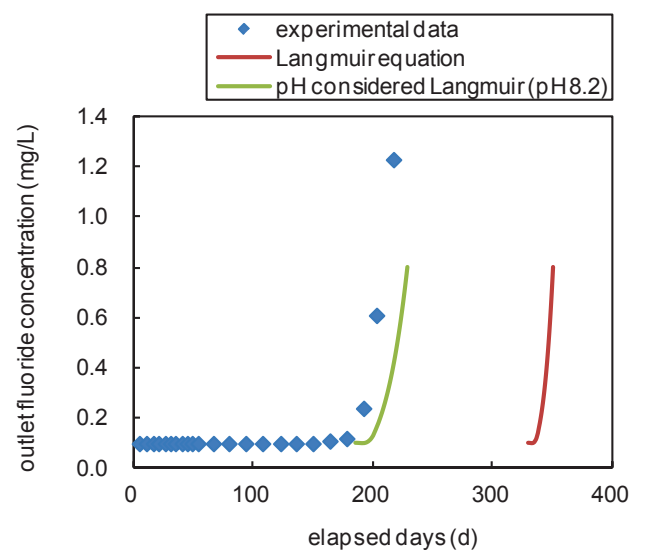

Fig. 7 Column experimental results.

\subsection{Experiments using actual contaminated groundwater}

Batch-wise and column adsorption experiments using actual fluoride-contaminated groundwater were also conducted in the present study. Actual fluoride-contaminated groundwater originated from hydrofluoric-acid used in factories from the electronic industry. The results from the batch-wise and column adsorption experiments are shown in Figs. 8 and 9 respectively.

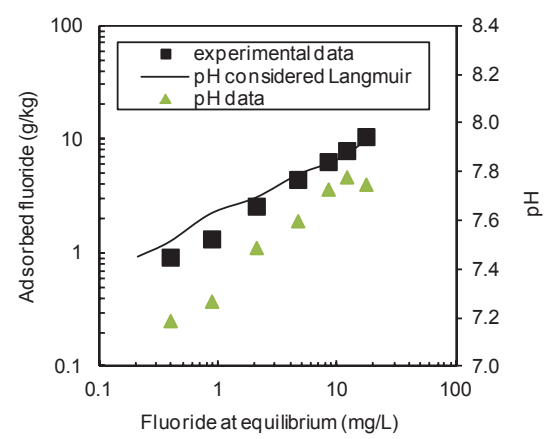

Fig. 8 Adsorption isotherm using actual contaminated groundwater.

The batch-wise experimental results for the adsorption parameters $q_{\mathrm{t}}=1.4 \mathrm{~mol} / \mathrm{kg}$ and $K_{\mathrm{ex}}=3 \times 10^{-4}$ at equilibrium were obtained by Eq. 7, which is the Langmuir isotherm with consideration of the aqueous solution $\mathrm{pH}$.

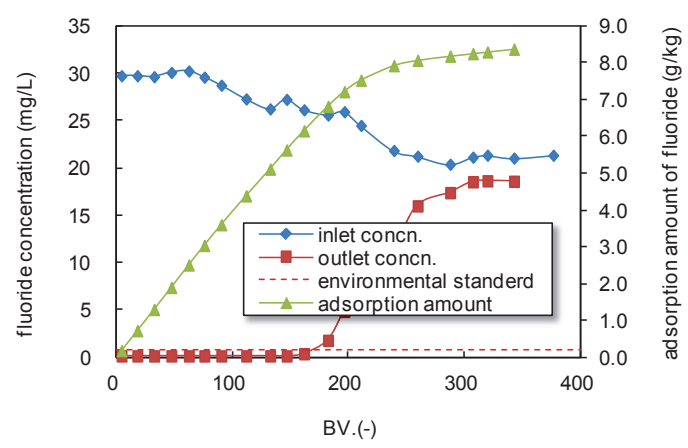

Fig. 9 Column adsorption profile using actual contaminated groundwater.

In this column experiment, the breakthrough began at around $170 \mathrm{BV}$ for the cumulative groundwater supply. The amount of adsorbed fluoride was $8.3 \mathrm{~g} / \mathrm{kg}$ (Fig. 9). In this experiment, the inlet concentration of fluoride was variable because the experiment continued while feeding several different samples of contaminated groundwater. Therefore, the average inlet fluoride concentration $(26 \mathrm{mg} / \mathrm{L})$ was used to calculate the amount of adsorption. Using Eq. 7, we calculated $7.7 \mathrm{~g} / \mathrm{kg}$ of fluoride was adsorbed at equilibrium from an aqueous solution containing $26 \mathrm{mg} / \mathrm{L}$. This estimation shows good agreement with the experimental results.

\subsection{Long-term stability of the adsorbent}

The VAS adsorbent used in this study was produced by baking allophane soil with iron(II) sulfate. Therefore, there is a possibility that the active functional groups were decomposed by hydrolysis. To confirm the long-term stability of VAS functional groups, a follow-up survey on the stability of adsorption performance was conducted by immersing VAS in water for a relatively long time. Fig. 10 shows the adsorption isotherm with intermittent measurements at predetermined intervals.

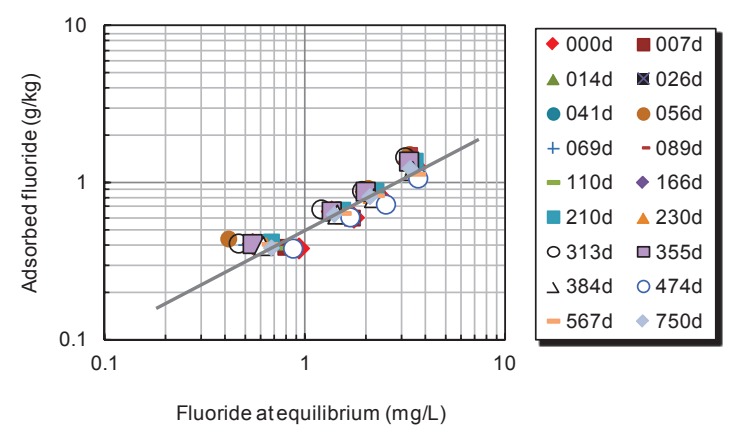

Fig. 10 Follow-up survey on the stability of adsorption performance of VAS immersed in water. 
During the evaluation period of $750 \mathrm{~d}$, there was no significant deterioration of the adsorption isotherm. Thus, in water, performance of the adsorption sites on VAS was maintained for a relatively long time.

\section{Conclusion}

Long-term stability of PRB performance is required for groundwater remediation. Therefore, it is necessary to understand the long-term performance of PRB stability and the reaction mechanism. The PRB should then be logically designed and based on the adsorption mechanism. In this study, technological information required for PRB design was obtained. The fluoride adsorption mechanism of VAS was clarified to be an ion-exchange reaction. The fluoride selectivity against the other anions in groundwater, the longterm performance stability, and the adsorption kinetic parameters confirm that VAS can be applied as a PRB material to remove fluoride from groundwater. As a consequence of this study, long-term PRB designing become possible.

\section{References}

1) ITRC (Interstate Technology \& Regulatory Council). 2011. Permeable Reactive Barrier: Technology Update. PRB-5. Washington, D.C., Available on the Internet at www.itrcweb.org.

2) M. Negishi, M. Fukazawa, M. Ariyama and Y. Fujii, Tikasui Dozyo Osen To Sono Bousi Ni Kansuru Kenkyuu Syuukai (Symposium on Soil and Groundwater Contamination and Remediation) Proceedings of the Tenth Symposium, 71, S119 (2004).

3) B. D. Turner, P. J. Binning and S. W. Sloana, Journal of Contaminant Hydrology, 95, 110 (2008).

4) B. D. Turner, P. J. Binning and S. W. Sloana, Environmental Engineering Science, 27, 64 (2010).

5) S P Mishra, M Das and U N Dash, Journal of Scientific \& Industrial Research, 69, 249 (2010).

6) R. E. Treybal, "Mass Transfer Operations", McGraw Hill (1967).

7) A. S. Michaels, Ind. Eng.Chem., 44, 1922 (1952). 